\title{
4-Aminopyridine Stimulates B-50 (GAP-43) Phosphorylation in Rat Synaptosomes
}

\author{
F.M.J. Heemskerk, L.H. Schrama, P.N.E. De Graan, and W.H. Gispen \\ Division of Molecular Neurobiology, Institute for Molecular Biology and Medical Biotechnology, Rudolf Magnus \\ Institute and Laboratory of Physiological Chemistry, University of Utrecht, Utrecht, The Netherlands
}

\begin{abstract}
Recently, we have shown that stimulation of $\left[{ }^{3} \mathrm{H}\right]$-noradrenaline release from hippocampal slices by 4 aminopyridine (4-AP) is accompanied by an enhancement of the phosphorylation of B-50, a major presynaptic substrate of protein kinase $\mathrm{C}(\mathrm{PKC})$. $\mathrm{PKC}$ has been implicated in the regulation of transmitter release. In this study, we investigated the effects of 4-AP on B-50 phosphorylation in synaptosomes from rat brain and compared the effects of 4-A.P with those of depolarization with $\mathrm{K}^{+}$, in order to gain more insight into the mechanism of action of 4-AP. B-50 phosphorylation was stimulated by incubation with 4-AP for 2 minutes at concentrations ranging from $10 \mu \mathrm{M}$ to $5 \mathrm{mM}$. 4-AP $(100 \mu \mathrm{M})$ stimulated B-50 phosphorylation already within $15 \mathrm{sec}-$ onds; longer incubations revealed a sustained increase in the presence of 4-AP. B-50 phosphorylation was also stimulated by depolarization with $30 \mathrm{mM} \mathrm{K}^{+}$for $15 \mathrm{sec}$ onds. The effects of both $4-\mathrm{AP}$ or $\mathrm{K}^{+}$depolarization on $\mathrm{B}-50$ phosphorylation were abolished at low extracellular $\mathrm{Ca}^{2+}$ concentrations. The increase in B-50 phosphorylation induced by 4-AP seemed to be dependent on the state of depolarization, since the effect of 4-AP was largest under nondepolarizing conditions. Comparing the effects of 4-AP and $\mathrm{K}^{+}$depolarization on B-50 phosphorylation suggests that a different mechanism of action is involved. These results indicate that the stimulation of B-50 phosphorylation by 4-AP in hippocampal slices can be attributed to a direct action of 4-AP on presynaptic terminals. In addition, our results support the hypothesis that B-50 phosphorylation by $\mathrm{PKC}$ is involved in $\mathrm{Ca}^{2+}$ dependent transmitter release evoked by $4-A P$.
\end{abstract}

4-AP is a drug inducing seizures (Szente and Baranyi, 1987), whereas application in vitro to hippocampal slices elicits epileptic bursting activity (Buckle and Haas, 1982; Voskuyl and Albus, 1985; Rutecki et al., 1987). Electrophysiological experi-

Address reprint requests to: Dr. L.H. Schrama, Institute of Molecular Biology and Medical Biotechnology, University of Utrecht, Padualaan 8, $3584 \mathrm{CH}$ Utrecht, The Netherlands.

This research was supported by CLEO-TNO grant A66 of the Dutch Epilepsy Foundation. ments have revealed that in excitable tissues 4-AP specifically blocks voltage-dependent $\mathrm{K}^{+}$channcls known to carry the A current (Segal et al., 1984; Rogawski, 1985). These channels are thought to play an important role in neuronal activity by regulating spike frequency (Segal et al., 1984; Rogawski, 1985). Although the drug is widely applied as a blocker of $\mathrm{K}^{+}$channels in electrophysiological experiments, little information is available on its impact on biochemical processes inside the cell.

One of the most striking features of 4-AP is that the drug is capable of stimulating release of many neurotransmitters in the PNS and the CNS. In brain, stimulatory effects of 4-AP on $\mathrm{Ca}^{2+}$ dependent transmitter release have been reported both in slices (Löffelholz and Weide, 1982; Doležal and Tuçek, 1983; Foldes et al., 1988; Heemskerk et al., 1990) and in synaptosomes (Tapia and Sitges, 1982; Tibbs et al., 1989).

The release of many transmitters is thought to be regulated by $\mathrm{Ca}^{2+} /$ phospholipid-dependent protein kinase C (PKC) (Augustine et al., 1987; Kaczmarek, 1987). Phorbol esters effective in activating PKC stimulate transmitter release (Allgaier et al., 1986; Versteeg and Florijn, 1986), whereas depolarization-evoked transmitter release can be attenuated by PKC inhibitors (Versteeg and Ulenkate, 1987; Hertting and Allgaier, 1988).

B-50 is a neuronal-tissue specific presynaptic phosphoprotein (Sörensen et al., 1981; Gispen et al., 1985; van Lookeren Campagne et al., 1989) with an acidic isoelectric point (4.5) and an apparent molecular weight of $48 \mathrm{kDa}$ on $11 \%$ SDS-polyacrylamide gels (Zwiers et al., 1980). It is identical to F1 (Gispen et al., 1986; Benowitz and Routtenberg, 1987), which has been implicated in long-term potentiation, to the growth-associated protein GAP-43 (Nielander et al., 1987; Basi et al., 1987), and to the calmodulin-binding protein neuromodulin/P57 (Cimler et al., 1987; for review see Skene, 1989). The phosphorylation of B-50, a major pre- 
synaptic substrate of PKC (Zwiers et al., 1980; Gispen et al., 1986; De Graan et al., 1988, 1989), has becn shown to be closely correlated with transmitter release (Dekker et al, 1989). In hippocampal slices phorbol esters stimulate B-50 phosphorylation as well as transmitter release (Dekker et al., 1989), whereas the phosphorylation of B-50 was also enhanced by depolarization with $30 \mathrm{mM} \mathrm{K}^{+}$. The latter effect was dependent on the presence of extracellular $\mathrm{Ca}^{2+}$ and was attenuated by the PKC inhibitor polymyxin B (Dekker et al., 1989).

Recently, we have found that 4-AP potently stimulated $\left[{ }^{3} \mathrm{H}\right]$-noradrenaline release from hippocampal slices (Heemskerk et al,, 1990). Concomitantly, 4-AP stimulated the phosphorylation of B-50 in these slices in a time- and concentration-dependent manner. Moreover, this effect of 4-AP was found to be PKC-mediated (Heemskerk et al., 1989a). We were interested resolving the mechanism by which 4-AP stimulates transmitter release. Depolarization of synaptosomes with $30 \mathrm{mM} \mathrm{K}^{+}$ has been shown to increase PKC activity (Wu et al., 1982; Rodnight and Perrett, 1986; Diaz-Guerra et al., 1988; Wang et al., 1988) and B-50 phosphorylation (Dekker et al., 1990). Therefore, in this study wc investigated the effects of 4-AP on the phosphorylation of B-50 in synaptosomes and compared these to the effects of $\mathrm{K}^{+}$depolarization on $\mathrm{B}-50$ phosphorylation, in order to gain more insight into the (presynaptic) mechanism of action of 4-AP.

\section{Materials and Methods}

\section{Isolation of Synaptosomes}

Cerebrocortical synaptosomes were obtained from male Wistar rats (100-150 g; TNO, Zcist, NL) according to the method of Dunkley et al. (1988). Synaptosomes separated on discontinuous Percollsucrose gradients (fraction 4) were washed twice in $40 \mathrm{ml}$ Krebs-Ringer buffer (KRB) [124 mM NaCl, $1.3 \mathrm{mM} \mathrm{MgSO}_{4}, 5 \mathrm{mM} \mathrm{KCl}, 2 \mathrm{mM} \mathrm{CaCl}, 26 \mathrm{mM}$ $\mathrm{NaHCO}_{3}, 10 \mathrm{mM}$ D-glucose, pH 7.4, thoroughly gassed with $95 \% \mathrm{O}_{2}-5 \% \mathrm{CO}_{2}$ (carbogen)], and collected at $11,000 \mathrm{~g}$ for $20 \mathrm{~min}$ using a SS-34 rotor. Subsequently, the pellet was resuspended in carbogenized KRB and kept on ice. The protein concentration was determined according to the method of Bradford (1976) using bovinc scrum albumin as a standard.

\section{Phosphate Labeling}

Synaptosomes $(2 \mu \mathrm{g} / \mu \mathrm{l})$ were incubated for $60 \mathrm{~min}$ utes under carbogen flow at $34^{\circ} \mathrm{C}$, with $1 \mu \mathrm{Ci} / \mu l{ }^{32} \mathrm{P}_{\mathrm{i}}$ (carrier free, Amersham, UK) in KRB in order to label the endogenous ATP pool with ${ }^{32} \mathrm{P}$, aliquoted $(10 \mu 1)$, and further incubated at $34^{\circ} \mathrm{C}$ (Dekker et al., 1990). Drugs were added (in a volume of $10 \mu \mathrm{l}$ ) at the times indicated in the text, maintaining a total incubation time of 10 minutes (unless stated otherwise in the text). The reaction was stopped by adding $10 \mu \mathrm{l}$ of ice-cold concentrated denaturing stop solution (final concentrations: $62.5 \mathrm{mM}$ Tris $\mathrm{HCl}, 2 \%$ SDS, $10 \%$ glycerol, $0.001 \%$ bromophenol blue, $5 \% 2$-mercaptoethanol, $\mathrm{pH} 6.5$ ). Elevated $\mathrm{K}^{+}$ concentrations in the buffer were always compensated by corresponding lower $\mathrm{Na}^{+}$concentrations, in order to avoid osmotic changes. In some experiments synaptosomes were diluted four times in $\mathrm{Ca}^{2+}$-free KRB with EGTA after labeling (at 4 $\mu \mathrm{g} / \mu \mathrm{l}$ ) in normal $\mathrm{KRB}$ (with $2 \mathrm{mM} \mathrm{Ca}^{2+}$ ), in order to reach low extracellular free $\mathrm{Ca}^{2+}$ conditions (final concentrations were: $0.5 \mathrm{mM} \mathrm{Ca}^{2+}$ and $2 \mathrm{mM}$ EGTA, resulting in an estimated free $\mathrm{Ca}^{2+}$ concentration below $10^{-7} \mathrm{M}$ ).

\section{Quantification and Expression of Data}

The amount of phosphate incorporation in B-50 was determined after quantitative immunoprecipitation, SDS-PAGE, and autoradiography (De Graan et al., 1989). In order to reduce aspecific precipitation of labeled material, a preclearing step (Dekker et al., 1990) was performed (involving incubation with the Staphylococcus aureus membranes used for the immunoprecipitation) before immunoprecipitation with specific anti-B-50 antibodies was carried out. B-50 phosphorylation was quantified by densitometric scanning of the autoradiograms. Changes in B-50 phosphorylation were expressed as percent of parallel control incubations (control $=100 \%)$ in order to compare the results of separate experiments. A two-tailed Student's $t$ test was used for statistical analysis of the results. Changes in total protein phosphorylation were assessed by SDS-PAGE ( $11 \%$ gel) followed by autoradiography or by precipitation of total proteins with trichloroacetic acid (TCA), as described by Schrama et al. (1984).

\section{Results}

4-AP-induced changes in presynaptic protein phosphorylation were investigated in $\left[{ }^{32} \mathrm{P}\right]$ orthophosphate-labeled synaptosomes. 4-AP $(100 \mu \mathrm{M})$ induced no overall changes in the phosphorylation pattern analyzed after separation by one-dimensional SDS-PAGE (Fig. 1A) nor in TCA-precipitable protein (results not shown), indicating that 4-AP had no general effect on the labeling of the ATP 


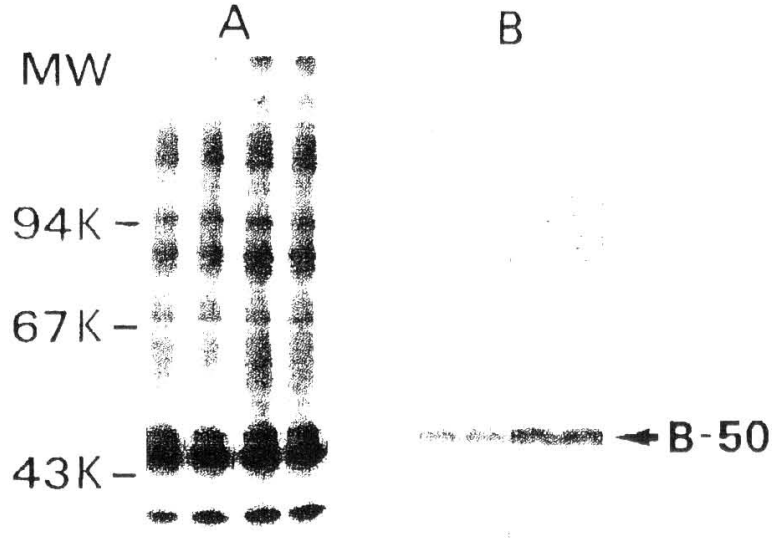

$30 K-$

Fig. 1. Effect of 4-AP on the phosphorylation of B-50 in rat cerebrocortical synaptosomes. $\left.{ }^{32} \mathrm{P}\right]$ orthophosphatelabeled synaptosomes were incubated for 2 minutes with buffer containing $100 \mu \mathrm{M} 4-\mathrm{AP}(+)$ or with control buffer $(-)$. The ${ }^{32} \mathrm{P}$ incorporation in proteins was analyzed by $11 \%$ SDS-PAGE and autoradiography. Autoradiograms show ${ }^{32} \mathrm{P}$ incorporation in total proteins $(\Lambda)$ and immunoprecipitated B-50 (B). N.B.: In (B) the autoradiogram was made by exposing the film for 63 hours using an intensifying screen, compared to direct exposure for 20 hours in (A); therefore the densities of lanes (A) are not directly comparable to those of lanes (B). Positions of molecular weight markers $(\mathrm{MW}$, in $\mathrm{kDa})$ are indicated on the left. The position of B-50 is indicated with an arrow on the right.

pool. No consistent changes because of 4-AP in individual major phosphobands were observed, except for an increase in the phosphorylation of a protein of $80-87 \mathrm{kDa}$ in a number of experiments (Fig. 1A). In this study we were mainly interested in changes in B-50 phosphorylation, therefore we did not investigate any changes in phosphorylation of this 80 to $87-\mathrm{kDa}$ protein in detail, although depolarization of synaptosomes with $\mathrm{K}^{+}$has been reported to enhance the phosphorylation of two proteins of a similar molecular weight (see Discussion).

Quantitative immunoprecipitation of B-50 and subsequent SDS-PAGE revealed an increase in B-50 phosphorylation 2 minutes after addition of $100 \mu \mathrm{M}$ 4-AP (Fig. 1B). It is not possible to detect changes in B-50 phosphorylation directly after onedimensional SDS-PAGE (N.B. in Fig. 1: the exposure times presented in panel $\mathrm{B}$ where much longer than those presented in panel $\mathrm{A}$, as explained in the legend).

The 4-AP-induced increase in B-50 phosphorylation was already detectable after 15 seconds (Fig. 2) and reached its maximum after 2 minutes (142 \pm $5 \%$ over control values). The phosphorylation of B-50 remained elevated for at least 15 minutes (121 $\pm 6 \%$, compared to controls, $P<0.01$ ). The magnitude of the increase in B-50 phosphorylation induced by treatment with 4-AP for 2 minutes depended on the 4-AP concentration applied (Fig. 3). The lowest concentration of 4-AP significantly stimulating B-50 phosphorylation was $10 \mu \mathrm{M}$, while 4-AP concentrations up to $5 \mathrm{mM}$ (the highest concentration tested) stimulated B-50 phosphorylation even further.

Since stimulation of B-50 phosphorylation by depolarization with $30 \mathrm{mM} \mathrm{K}$ is only observed in the presence of extracellular $\mathrm{Ca}^{2+}$ (Dekker et al., 1989, 1990), we investigated the effects of 4-AP on B-50 phosphorylation at low extracellular $\mathrm{Ca}^{2+}$ concentrations $\left(<10^{-7} \mathrm{M}\right)$. [ $\left.{ }^{32} \mathrm{P}\right]$ Orthophosphate-labeled synaptosomes were incubated for 10 minutes in $\mathrm{KRB}$ with $\mathrm{Ca}^{2+}(2 \mathrm{mM})$ or with low extracellular $\mathrm{Ca}^{2+}$ (with EGTA added), and 4-AP was added 2 minutes before the reaction was stopped. Parallel samples were depolarized with $30 \mathrm{mM} \mathrm{K}^{+}$for 15 seconds under these two $\mathrm{Ca}^{2+}$ conditions, before terminating the reaction. As can be seen in Fig. 4, B-50 phosphorylation in $\mathrm{KRB}$ with $\mathrm{Ca}^{2+}$ was stimulated by $100 \mu \mathrm{M} 4-\mathrm{AP}$, as well as by depolarization. Chelation of extracellular calcium with EGTA decreased basal phosphorylation of B-50 to $82 \% \pm 5$ $(P<0.05)$. Under these conditions neither 4-AP

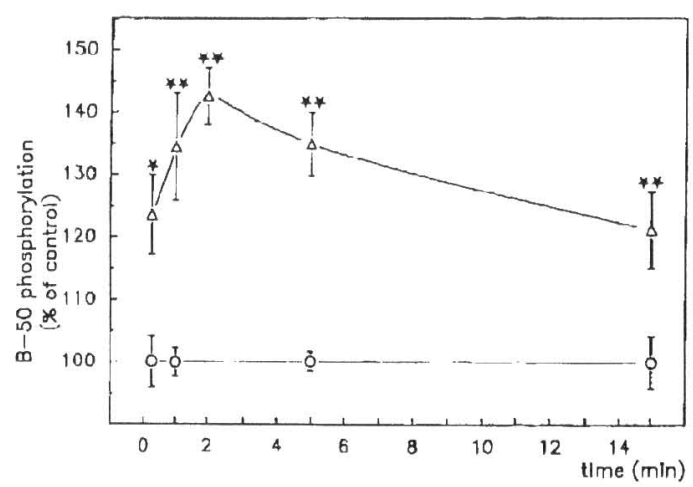

Fig. 2. Time course of the effect of 4-AP on B-50 phosphorylation. After incubation with $100 \mu \mathrm{M}$ 4-AP (triangles) or control buffer (circles), B-50 phosphorylation was determined as described in the legend of Fig. 1. Data are expressed as percent ( \pm SEM) of controls incubated for $5 \mathrm{~min}(=100 \%)$. Significant differences are indicated: ${ }^{\star} P<0.05,{ }^{\star} P<0.01$. 


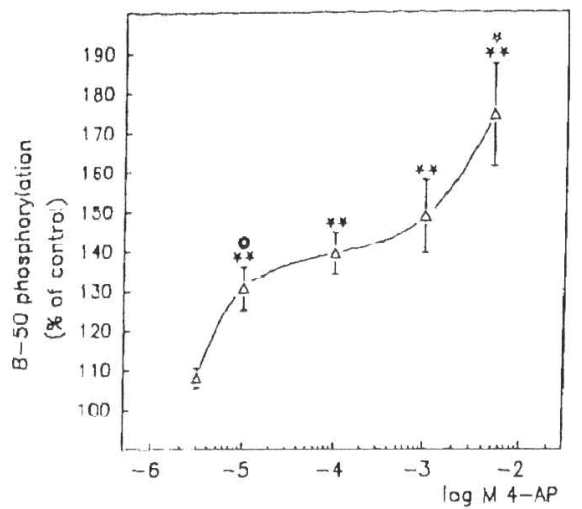

Fig. 3. Dose-response curve of 4-AP on the phosphorylation of B-50. B-50 phosphorylation was determined 2 minutes after addition of 4-AP as described in the legend of Fig. 1. Data are expressed as percent ( \pm SEM) of B-50 phosphorylation in control incubations. Significant differences are indicated: ${ }^{\star} P<0.01$. Differences between $10 \mu \mathrm{M} 4$-AP and $3 \mu \mathrm{M} 4$-AP (resp. $5 \mathrm{mM} 4$-AP) were significant: $O P<0.05$ (resp. ${ }^{\circ} P<0.01$ ).

nor $\mathrm{K}^{4}$ depolarization significantly affected $\mathrm{B}-50$ phosphorylation (Fig. 4).

As both $\mathrm{K}^{+}$depolarization and 4-AP stimulated B-50 phosphorylation in a $\mathrm{Ca}^{2+}$-dependent manner, we investigated whether these stimulatory effects were additivc (Fig. 5). Indeed, at half-maximal

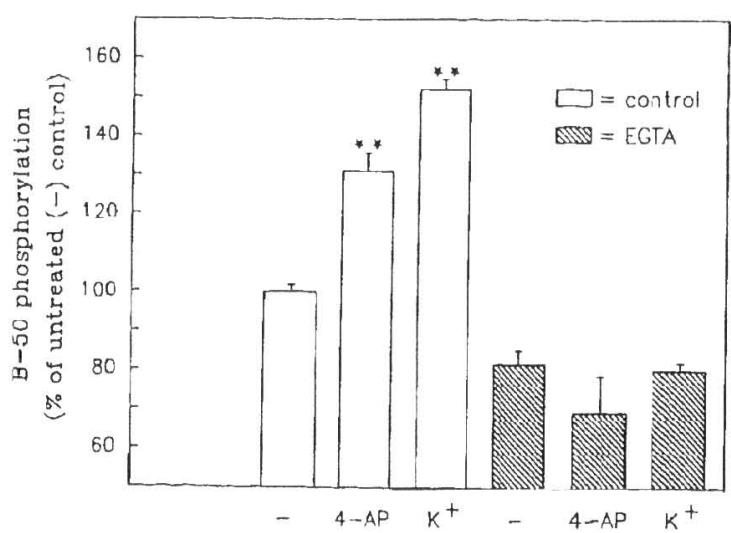

Fig. 4. $\mathrm{Ca}^{2+}$-dependency of stimulation of B-50 phosphorylation by 4-AP or $\mathrm{K}^{+}$depolarization. B-50 phosphorylation was determined as described in the legend of Fig. 1, after incubation in $\mathrm{KRB}(-)$ or in the presence of $100 \mu \mathrm{M}$ 4-AP (4-AP) or $30 \mathrm{mM} \mathrm{K}^{+}\left(\mathrm{K}^{+}\right)$. Data are expressed as percent ( \pm SEM) of control incubations $(2 \mathrm{mM}$ $\left.\mathrm{CaCl}_{2}\right)$ without 4-AP $\left(5 \mathrm{mM} \mathrm{K}{ }^{+}\right)$. Total incubation time in $2 \mathrm{mM} \mathrm{CaCl}_{2}$ (control) or $\sim 10^{-7} \mathrm{M} \mathrm{Ca}^{2+}$ (EGTA) was 10 minutes. 4-AP was present for the last 2 minutes, $30 \mathrm{mM}$ $\mathrm{K}^{+}$for the last 15 seconds of the incubation. Significant differences are indicated: $\star P<0.01$ [compared to control incubations $\left(2 \mathrm{mM} \mathrm{CaCl}_{2}\right)$ ]. stimulation with $18 \mathrm{mM} \mathrm{K}^{+}, 100 \mu \mathrm{M}$ 4-AP further stimulated B-50 phosphorylation (Fig. 5A). However, at maximal stimulation by $30 \mathrm{mM} \mathrm{K}^{+}, 100$ $\mu \mathrm{M}$ 4-AP did nor further enhance B-50 phosphorylation (Fig. 5A). In Fig. 5B the time course of the effects of prolonged incubation with $\mathrm{K}^{+}$or $100 \mu \mathrm{M}$ 4-AP on B-50 phosphorylation are shown. During incubation of synaptosomes with $30 \mathrm{mM} \mathrm{K}^{+}, \mathrm{B}-50$ phosphorylation is transiently enhanced with a maximum at 15 seconds and returns to control levels within 5 minutes (see also Dekker et al., 1990). In contrast, incubation in the presence of $100 \mu \mathrm{M} 4-\mathrm{AP}$ and $30 \mathrm{mM} \mathrm{K}{ }^{+} \mathrm{B}-50$ phosphorylation remained significantly elevated above control levels $(P<0.05)$ for at least 5 minutes.

\section{Discussion}

We have reported that 4-AP stimulated transmitter release in hippocampal slices and concomitantly increased B-50 phosphorylation (Heemskerk et al., 1990). The changes in B-50 phosphorylation in synaptosomes induced by 4-AP described in this paper are similar to those induced by 4 -AP in hippocampal slices, with respect to time as well as concentration dependency (Heemskerk et al., 1990). This indicates that the effects of 4-AP on the phosphorylation of B-50 in hippocampal slices can be attributed to a direct action of 4-AP on presynaptic terminals.

In some experiments we observed an increased phosphorylation of a 80 to $87-\mathrm{kDa}$ band by $4-\mathrm{AP}$ (Fig. 1). Although we did not investigate the identity of this phosphoband in detail, it could either be synapsin I or the 87-kDa substrate of PKC. Phosphorylation of synapsin I by $\mathrm{Ca}^{2+} /$ calmodulin-dependent kinase II has been shown to facilitate transmitter release (Llinás et al., 1985; Colbran et al., 1989), and the phosphorylation of both proteins was found to be enhanced upon depolarization of synaptosomes, possibly as a result of $\mathrm{Ca}^{2+}$ influx (Wu et al., 1982; Dunkley and Robinson, 1986; Rodnight and Perrett, 1986; Wang et al., 1988).

There appears to be a close correlation between the effects of 4-AP on B-50 phosphorylation and $\mathrm{Ca}^{2+}$-dependent transmitter release in synaptosomes. It has been reported that 4-AP stimulates the release of several transmitters from synaptosomes in a $\mathrm{Ca}^{2+}$-dependent manner (Tapia and Sitges, 1982; Tibbs et al., 1989). Interestingly, 4-AP enhanced spontaneous transmitter release but was not able to stimulate release under depolarizing conditions (Tapia and Sitges, 1982). 4-AP affected 


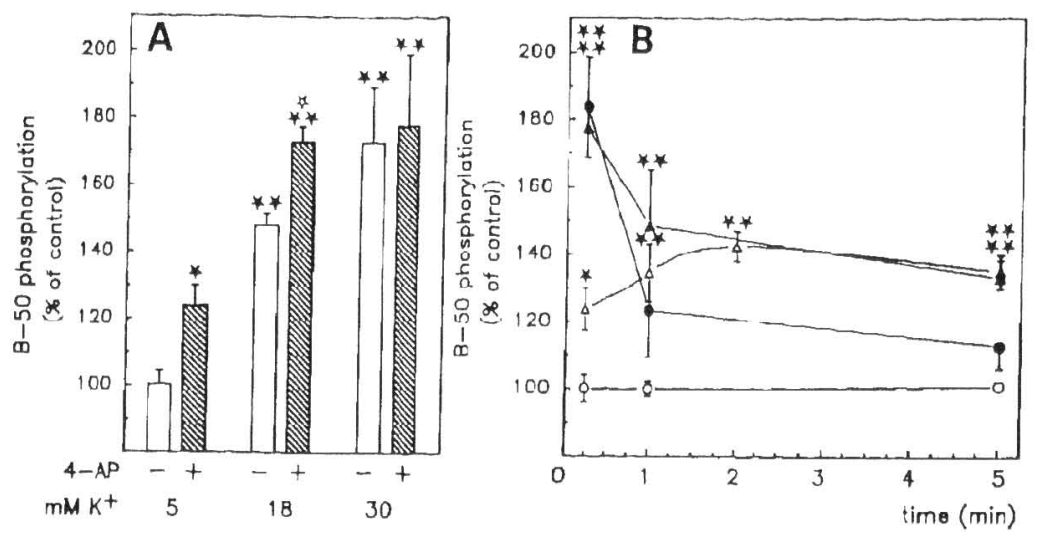

Fig. 5. Effects of 4-AP and $\mathrm{K}^{+}$depolarization on B-50 phosphorylation. B-50 phosphorylation was determined as described in the legend of Fig. 1. (A) Effects of incubation for 15 seconds in the presence of 18 or $30 \mathrm{mM} \mathrm{K} \mathrm{K}^{+}$, with (+) or

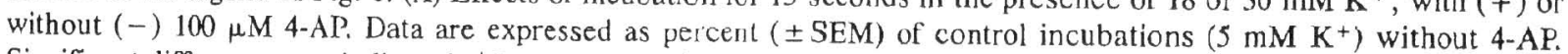
Significant differences are indicaled: ${ }^{\star} P<0.05$ and ${ }^{\star} P<0.01$ (compared to control incubation in the presence of $5 \mathrm{mM}$ $\mathrm{K}^{+}$) and ${ }^{+} P<0.01$ (incubated with 4-AP in the presence of $18 \mathrm{mM} \mathrm{K}+$ compared to incubations in the presence of $18 \mathrm{mM}$ $\mathrm{K}^{+}$alone). (B) Time course of $\mathrm{B}-50$ phosphorylation after incubation in the presence (triangles) or in the absence (circles) of $100 \mu \mathrm{M} 4$-AP under normal ( $5 \mathrm{mM} \mathrm{K} \mathrm{K}^{+}$, open symbols) or depolarized conditions ( $30 \mathrm{mM} \mathrm{K} \mathrm{K}^{+}$, filled symbols). Data are expressed as percent $\left( \pm\right.$ SEM) of control incubations $\left(5 \mathrm{mM} \mathrm{K}^{+}\right)$without 4-AP. Significant differences are indicated: ${ }^{\star} P$ $<0.05$ and $\star P<0.01$ (compared to parallel control incubations in the presence of $5 \mathrm{mM} \mathrm{K} \mathrm{K}^{+}$).

transmitter release in those studies in the same dose range as B-50 phosphorylation ( $\mathrm{Hig}$. 3). Similar to its effects on transmitter release, 4-AP stimulates B-50 phosphorylation only under nondepolarizing conditions (Fig. 5) and in a $\mathrm{Ca}^{2+}$-dependent manner (Fig. 4).

The $\mathrm{Ca}^{2}+$ dependency of the effects of 4-AP and $\mathrm{K}^{+}$suggests that $\mathrm{Ca}^{2+}$ influx might be involved in the stimulation of B-50 phosphorylation. Although depolarization with $\mathrm{K}^{+}$and 4-AP both stimulate $\mathrm{Ca}^{2+}$-dependent release and increase B-50 phosphorylation, there are some important differences. Chemical depolarization of synaptosomes with $\mathrm{K}^{+}$ stimulates B-50 phosphorylation within 15 seconds to a maximal level (Fig. 5) (Dekker et al., 1990), whereas stimulation of B-50 phosphorylation by 4-AP is much slower, reaching its maximal level not before 2 minutes (Fig. 2). Moreover, stimulation of B- 50 phosphorylation in the presence of $30 \mathrm{mM} \mathrm{K}^{+}$ seems to be a transient phenomenon, while 4-AP induces a sustained stimulation of B-50 phosphorylation. Since the effects of $4-\mathrm{AP}$ and $30 \mathrm{mM} \mathrm{K}^{+}$ were not additive, they are apparently not independent (see Fig. 5). This implies that one of the steps leading to B-50 phosphorylation was already maximally stimulated by $30 \mathrm{mM} \mathrm{K} \mathrm{K}^{+} . \mathrm{K}^{+}$at $18 \mathrm{mM}$ is known to stimulate $\mathrm{Ca}^{2+}$ entry and transmitter release from synaptosomes submaximally (Cotman et al., 1976; Nachshen and Blaustein, 1980; Nachshen, 1985). Stimulation of B-50 phosphorylation with $18 \mathrm{mM} \mathrm{K}^{+}$indeed allowed an additional stimulation by $4-A \mathrm{P}$ to a level of $\mathrm{B}-50$ phosphorylation that was not significantly different from that by 30 $\mathrm{mM} \mathrm{K}^{+}$.

Together with the results shown in Fig. 4, the data described above indicate that, although $\mathrm{Ca}^{2+}$ influx might be involved in the increase of B-50 phosphorylation, the effect of 4-AP on B-50 phosphorylation seems to be dependent on the state of depolarization. Many authors have suggested that 4-AP is able to enhance $\mathrm{Ca}^{2+}$ entry (Thesleff, 1980) either directly (Lundh and Thesleff, 1977; Rogawski and Barker, 1983; Agoston et al., 1983) or indirectly by blocking $\mathrm{K}^{+}$channels (Segal et al., 1984; Rogawski, 1985). However, only a few experiments have been described investigating the effects of 4-AP on $\mathrm{Ca}^{2+}$ entry directly, A stimulation of ${ }^{45} \mathrm{Ca}^{2+}$ uptake of synaptosomes by 4 -AP or its structural analog 3,4-diaminopyridine was reported by some investigators (Agoston et al., 1983; Peterson and Gibson, 1983, 1985) but was not found by others (Tapia et al., 1985). Gibson and Manger (1988) reported that 4-AP caused, within seconds, an increase in the cytosolic free $\mathrm{Ca}^{2+}$ concentration in synaptosomes under nondepolarizing conditions, as determined with the fluorescent dye Fura-2. Recently, these results have been confirmed (Heemskerk et al., 1989b; Nicholls et al., 1989).

Taken together, the available data support an stimulatory effect of 4-AP on $\mathrm{Ca}^{2+}$ influx in synaptosomes under nondepolarizing conditions. Consequently, we hypothesize that 4-AP might enhance B-50 phosphorylation and transmitter release by stimulating $\mathrm{Ca}^{2+}$ influx. 
Acknowledgments: The authors would like to acknowledge Ed Kluis and Sander Reintjes for the artwork, Drs. A.B. Oestreicher and L.V. Dekker for the B-50 antiserum 8502, and Marina de Wit for experimental assistance.

\section{References}

Allgaier C., Von Kügelgen O., Hertting G. (1986). Enhancement of noradrenaline release by 12 - $O$-tetradecanoyl phorbol-13-acetate, an activator of protein kinase C. Eur. J. Pharmacol. 129:389-392

Augustine G.J., Charlton M.P., Smith S.J. (1987). Calcium action in synaptic transmitter release. Annu. Rev. Neurosci. 10:633-693

Agoston D., Hargittai P., Nagy A. (1983). Effects of 4aminopyridine in calcium movements and changes of membrane potential in pinched-off nerve terminals from rat cerebral cortex. J. Neurochem. 41:745-751

Basi G.S., Jacobson R.D., Virág I., Schilling J., Skene J.H.P. (1987). Primary structure and transcriptional regulation of GAP43, a protein associated with nervegrowth. Cell 49:785-791

Benowitz L.I., Routtenberg A. (1987). A membrane phosphoprotein associaled with neural development, axonal regeneration, phospholipid metabolism, and synaplic plasticity. Trends Neurosci. 10:527-532

Bradford M.M. (1976). A rapid and sensitive method for the quantification of microgram quantities of protein utilizing the principle of dye-binding. Anal. Biochem. 72:248-254

Buckle P.J., Haas H.L. (1982). Enhancement of synaptic transmission by 4 -aminopyridine in hippocampal slices of the rat. J. Physiol. 326:109-122

Cimler B.M., Giebelhaus D.H., Wakim B.T., Storm D.R., Moon R.T. (1987). Characterization of murine cDNAs encoding P-57, a neural-specific calmodulinbinding protein. J. Biol. Chem. 262:12158-12163

Colbran R.J., Schworer C.M., Hashimoto Y, Fong Y. L., Rich D.P., Smith M.K., Soderling T.R. (1989). Calcium/calmodulin-dependent protein kinase II. Biochem J. 258:313-325

Cotman C.W., Haycock J.W., White F.F. (1976). Stimulus-secretion processes in brain: Analysis of noradrenaline and GABA release. J. Physiol. London 254:475505

De Graan P.N.E., Heemskerk F.M.J., Dekker L.V., Melchers B.P.C., Gianotti C., Schrama L.H. (1988). Phorbol esters induce long- and short-term enhance ment of B-50/GAP-43 phosphorylation in rat hippocampal slices. Neurosci. Res. Commun. 3:175-182

De Graan P.N.E., Dekker, L.V., Oestreicher A.B., Van der Voorn L., Gispen W.H. (1989). Determination of changes in the phosphorylation state of the neuronspecific protein kinase C substrate B-50 (GAP43) by quantitative immunoprecipitation. J. Neurochem. 52:17-23

Dekker L.V., De Graan P.N.E., Versteeg D.H.G., Oestreicher A.B., Gispen W.H. (1989). Phosphorylation of B-50 (GAP43) is correlated with neurotransmitter re- lease in rat hippocampal slices. J. Neurochem. 52:2430

Dekker L.V., De Graan P.N.E., De Wit M., Hens J.J.H., Gispen W.H. (1990). Depolarization-induced phosphorylation of the protein kinase C substrate B-50 (GAP43) in rat cortical synaptosomes. J. Neurochem. 54:in press

Diaz-Guerra M.J.M., Sánchez-Prieto J., Bosca L., Pocock J., Barric A., Nicholls D. (1988). Phorbol ester translocation of protein kinase $\mathrm{C}$ in guinea-pig synaptosomes and the potentiation of calcium-dependent glutamate release. Biochim. Biophys. Acta 970:157165

Doležal V., Tuçek S. (1983). The effects of 4-aminopyridine and tetrodotoxin on the release of acetylcholine from rat striatal slices. Naunyn-Schiedeberg's Arch. Pharmacol. 323:90-95

Dunkley P.R., Robinson P.J. (1986). Depolarisation-dependent protein phosphorylation in synaptosomes: Mechanisms and significance. Prog. Brain Res. 69:273-293

Dunkley P.R., Heath J.W., Harrison S.M., Jarvie P.E., Glenfield P.J., Rostas A.P. (1988). A rapid Percoll gradient procedure for isolation of synaptosomes directly from an S1-fraction: Homogeneity and morphology of subcellular fractions. Brain Res. 441:59-71

Foldes F.F., Ludvig N., Nagashima H., Vizi E.S. (1988), The influence of aminopyridines on $\mathrm{Ca}^{2+}$-dependent evoked release of acetylcholine from rat cortex slices. Neurochem. Res. 13:761-764

Gibson G.E., Manger T. (1988). Changes in cytosolic free calcium with 1,2,3,4-tetrahydro-5-aminoacridine, 4aminopyridine and 3,4-diaminopyridine. Biochem. Pharmacol. 37:4191-4196

Gispen W.II., Leunissen J.L.M., Oestreicher A.B. Verkleij A.J., Zwiers H. (1985). Presynaptic localization of B-50 phosphoprotein: The (ACTH)-sensitive protein kinase substrate involved in rat brain polyphosphoinositide metabolism. Brain Res. 328:381-385

Gispen W.H., De Graan P.N.E., Chan S.Y., Routtenberg A. (1986). Comparison between the neural acidic proteins B-50 and F1. Prog. Brain Res. 69:383-386

Heemskerk F.M.J., Schrama L.H., De Graan P.N.E., Ghijsen W.E.J.M., Lopes da Silva F.II., Gispen W.H. (1989a). 4-Aminopyridine increases B-50 (GAP-43) phosphorylation and calcium levels in rat brain synaptosomes. Am. Neurosci. Abstr. 189.15

Heemskcrk F.M.J., Schrama L.H., Ghijsen W.E.J.M., De Graan P.N.E., Lopes da Silva F.H., Gispen W.H. (1989b). Increased B-50/GAP-43 phosphorylation and $\mathrm{Ca}^{2+}$ levels in synaptosomes by 4 -aminopyridine. $\mathrm{J}$. Neurochem. Suppl. 52:106B

Heemskerk F.M.J., Schrama L.H., Gianotti C., Spierenburg H., Versteeg D.H.G., De Graan P.N.E., Gispen W.H. (1990). 4-Aminopyrdine stimulates B-50/GAP-43 phosphorylation and $\left[{ }^{3} \mathrm{H}\right]$-noradrenaline release in rat hippocampal slices. J. Neurochem. 54:in press

Hertting G., Allgaier C. (1988). Participation of protein kinase $C$ and regulatory $G$ proteins in modulation of the evoked noradrenaline release in brain. Cell. Mol. Neurobiol. 8:105-114 
Kaczmarek L.K. (1987). The role of PKC in regulation of ion channels and neurotransmitter release. Trends Neurosci. 10:30-34

Llinás R., McGuiness T.L., Leonard C.S., Sugimori M., Greengard P. (1985). Intraterminal injection of synapsin I or calcium/calmodulin-dependent protein kinase II alters neurotransmitter release in the squid giant synapse. Proc. Natl. Acad. Sci. U.S.A. 82:3035-3039

Löffelholz K., Weide W. (1982). Aminopyridines and the release of acetylcholine. Trends Pharmacol. Sci. 4: $147-149$

Lundh H., Thesleff S. (1977), The mode of action of 4aminopyridine and guanidine on transmitter release from motor nerve terminals. Eur. J. Pharmacol. 42 : 411-412

Nachshen D.A. (1985). Regulation of cytosolic calcium concentration in presynaptic nerve endings isolated from rat brain. J. Physiol. 363:87-101

Nachshen D.A., Blaustein M.P. (1980). Some properties of potassium-stimulated calcium influx in presynaptic nerve endings. J. Gen. Physiol. 76:709-728

Nicholls D.G., Tibbs G., Barrie A.P. (1989). Cytosolic free calcium in synaptosomes and its coupling to glutamate exocytosis. J. Neurochem. Suppl. 52:47D

Nielander H.B., Schrama L.H., Van Rozen A.J., Kasperaitis M., Oestreicher A.B., De Graan P.N.E., Gispen W.H., Schotman P. (1987). Primary structure of the ncuron-specific phosphoprotein B-50 is identical to growth-associated protein GAP-43. Neurosci. Res. Commun. 1:163-172

Peterson C., Gibson G.E. (1983). Aging and 3,4-diaminopyridine alter synaptosomal calcium uptake. J. Biol. Chem. 258:11482-11486

Peterson C., Gibson G.E. (1985). Synaptosomal calcium metabolism during hypoxia and 3,4-diaminopyridine treatment. J. Neurochem. 42:248-253

Rodnight R., Perrett C. (1986). Protein phosphorylation and synaptic transmission: Receptor mediated modulation of protein kinase $C$ in a rat brain fraction enriched in synaptosomes. J. Physiol. (Paris) 81:340348

Rogawski M.A. (1985). The A-current: How ubiquitous a feature of excitable cells is it? Trends Neurosci. 5: 214-219

Rogawski M.A., Barker J.L. (1983), Effects of 4-aminopyridine on calcium action potentials and calcium current under voltage clamp in spinal neurons. Brain Res. 280: $180-185$

Rutecki P.A., Lebeda F.J., Johnston D. (1987), 4-Aminopyridine produces cpileptiform activity in hippocampus and enhances synaptic excitation and inhibition. J. Neurophysiol. 57:1922-1924

Schrama L.H., Edwards P.M., Schotman P. (1984). Modulation of protein synthesis in a cell-free system derived from rat brain by corticotropin (ACTH), magnesium, and spermine. J. Neurosci. Res. 11:67-77

Segal M., Rogawski M.A., Barker J.L. (1984). A tran- sient potassium conductance regulates the excitability of cultured hippocampal and spinal neurons. J. Neurosci. 4:604-609

Skene J.H.P. (1989). Axonal growth-associated proteins. Annu. Rev. Neurosci. 12:127-156

Sörensen R.G., Kleine L.P., Mahler H.R. (1981). Presynaptic localization of phosphoprotein B-50. Brain Res. Bull. 7:57-61

Szente M., Baranyi A. (1987). Mechanism of aminopyridine-induced ictal seizure activity in the cat neocortex. Brain Res. 413:368-373

Tapia R., Sitges M. (1982). Effect of 4-aminopyridine on transmitter release in synaptosomes. Brain Res. 250: 291-299

Tapia R., Sitges M., Morales E. (1985). Mechanism of the calcium-dependent stimulation of transmitter release by 4-aminopyridine in synaptosomes. Brain Res. 361:373-382

Iibbs G.R., Dolly J.O., Nicholls D.G. (1989). Dendrotoxin, 4-aminopyridine and $\beta$-bungarotoxin act at common loci but by two distinct mechanisms to induce $\mathrm{Ca}^{2+}$-dependent release of glutamate from guinea-pig cerebrocortical synaptosomes. J. Neurochem. 52:201-206

Thesleff S. (1980) Aminopyridines and synaptic transmission. Neuroscience 5:1413-1419

Van Lookeren Campagne M., Oestreicher A.B., Van Bergen en Henegouwen P.M.P., Gispen W.H. (1989). Ultrastructural immunocytochemical localization of $\mathrm{B}-50 / \mathrm{GAP} 43$, a protein kinase $\mathrm{C}$ substrate, in isolated presynaptic nerve terminals and neuronal growth cones. J. Neurocytol. 18:479-489

Versteeg D.H,G., Florijn W.J. (1986). Phorbol 12,13-dibutyrate enhances electrically stimulated neuromessenger release from rat dorsal hippocampal slices in vitro. Life Sci, 40:1237-1243

Versteeg D.H.G., Ulenkate H.J.L.M. (1987). Basal and electrically stimulated release of $\left[{ }^{3} \mathrm{H}\right]$ noradrenaline and $\left[{ }^{3} \mathrm{H}\right]$ dopamine from rat amygdala slices in vitro: Effects of 4-phorbol 12,13-dibutyrate, $4 \alpha-12,13$-didecanoate and polymyxin B. Brain Res. 416:343-348

Yoskuyl R.A., Albus H. (1985). Spontaneous epileptiform discharges in hippocampal slices induced by 4 . aminopyridine. Brain Res. 342:54-66

Wang J.K.T., Walaas S.I., Greengard P. (1988), Protein phosphorylation in nerve terminals: Comparison of calcium/calmodulin-dependent and calcium/diacylglyccrol-dependent systems. J. Neurosci. 8:281-288

Wu W.C.-S., Waladas S.I., Nairn A.C., Greengard P. (1982). Calcium/phospholipid regulates phosphorylation of a Mr " $87 \mathrm{k}$ " substrate protein in rat brain synaptosomes. Proc. Natl. Acad. Sci. U.S.A. 79:52495253

Zwiers H., Schotman P., Gispen W.H. (1980). Purification and some characteristics of an ACTH-sensitive protein kinase and its substrate protein in rat brain membranes. J. Neurochem. 34:1689-1699 